\title{
Overexpression of NLRC3 enhanced inhibition effect of sevoflurane on inflammation in an ischaemia reperfusion cell model
}

\author{
Wei $\mathrm{Li}^{1}$, Yu Zhang ${ }^{2}$, Zhenhua $\mathrm{Hu}^{3}$, Yanbing $\mathrm{Xu}^{1}$ \\ ${ }^{1}$ Department of Anaesthesia, Shandong Provincial Hospital Affiliated to Shandong First Medical University, Shandong, China, \\ ${ }^{2}$ Department of Geriatrics, Qilu Hospital of Shandong University, Shandong, China, ${ }^{3}$ Department of Anaesthesia, Shandong \\ Chengwu People's Hospital, Shandong, China
}

\begin{abstract}
Brain ischaemia is one of the leading causes of mortality and disability worldwide, and the damage caused by ischaemia not only induces primary damage but also that induced by ischaemia-reperfusion (I/R) injury. Multiple processes including inflammation and oxidative stress response play important roles in the development of brain ischaemia injury. Sevoflurane is a well-known volatile anaesthetic, and a recent study discovered the role of sevoflurane in suppression of the inflammation response process via inhibition of inflammatory infiltrates and production, maintaining the balance of cytokine responses, although the possible mechanism was not fully clear. NLRC3 is a member of the nucleotide-binding domain and leucine-rich repeat containing (NLR) family, and it has been regarded as a regulator of the inflammation process via the regulation of inflammasome formation, which is an initiator of inflammatory events. In the present study, we found that overexpression of NLRC3 reduced the apoptosis in a cellular model of ischaemia reperfusion, and the expression of pro-inflammatory cytokines was also decreased. Further study found that these effects might be mediated by the TRAF6/TLR4/NF-אB signalling pathway. Thus, we speculate that overexpression might enhance the effect of sevoflurane in inhibiting the inflammatory response process in an ischaemia reperfusion model, which might be a new therapeutic strategy.
\end{abstract}

Key words: ischaemia reperfusion, NLRC3, sevoflurane, inflammation.

\section{Introduction}

Cerebral ischaemia is one of the leading causes of death and disability around the world. Early restoration of blood flow is important for the treatment of cerebral ischaemia, but the apoptosis of neuronal cells still occurs after the restoration of blood flow. These processes are thought to be mediated by activation of pro-inflammation factors including cytokines, nitric oxide, and free radicals [28]. How- ever, the effective treatment for cerebral ischaemia is still lacking because multiple signalling pathways are only partially effective [41]. A recent study revealed that some anaesthetics possess a neuroprotective role, including isoflurane, sevoflurane, and desflurane. Among them, sevoflurane presented short-term (72 to $96 \mathrm{~h}$ ) and long-term (28 days) neuroprotective effects in focal or global cerebral ischaemia [34]. A previous study found that sevoflurane could pre-

\section{Communicating author}

Yanbing Xu, Department of Anaesthesia, Shandong Provincial Hospital Affiliated to Shandong First Medical University, No. 324 Jingwu Road, Jinan, Shandong, China, 250021, e-mail: vvxovo@outlook.com 
vent the deficit in cognitive function induced by ischaemia when compared with a fentanyl treatment group [8]. However, the detailed mechanism was not clear. NOD-like receptor family CARD domain containing 3 (NLRC3) is an important suppressor of the inflammatory response in multiple species [45], and a recent study noted that NLRC3 is also an important regulator of the inflammatory response in a model of ischaemia reperfusion, because overexpression of NLRC3 alleviated the inflammation process induced by ischaemia reperfusion [24]. Thus, we speculated that overexpression of NLRC3 might also contribute to the effects of sevoflurane in the treatment of cerebral ischaemia. Herein, we established the an NLRC3 overexpression and knockdown model in PC12 cells, and we found that overexpression of NLRC3 reduced the apoptosis process in PC12 cells, while further study found that these processes might be mediated by inhibition of the expression of pro-inflammatory factors. Finally, we found that overexpression of NLRC3 promotes the survival of PC12 cells via regulation of the TRAF6/TLR4/NF- $\kappa$ B signalling pathway and its downstream molecules.

\section{Material and methods \\ Cell culture and grouping}

PC12 cells (CRL-1721) were purchased from ATCC. Cells were cultured under $37^{\circ} \mathrm{C}$ temperature with $5 \%$ $\mathrm{CO}_{2}$ in RPMI-1640 medium supplied with $10 \%$ fetal bovine serum (FBS). In order to construct an in vitro ischaemia reperfusion model in PC12 cells, cells were cultured in glucose-free Earl's balanced salt solution with a $95 \% \mathrm{~N}_{2}$ and $5 \% \mathrm{CO}_{2}$ atmosphere, and after $4 \mathrm{~h}$ of incubation, the medium was replaced with RPMI-1640, and cells were cultured under normal conditions for $24 \mathrm{~h}$ [46]. Then, cells were divided into four groups: a model group $(M)$, single sevoflurane treatment group (S), sevoflurane treatment combined with NLRC3 overexpression group (O), and a sevoflurane treatment combined with NLRC3 inhibition group (I). In the sevoflurane treatment group, cells were treated with $2.4 \%$ (v/v) sevoflurane for $20 \mathrm{~min}$ at the end of ischaemia reperfusion model construction [14].

\section{Vector construction}

In order to construct the NLRC3 overexpression vector, CDNA of NLRC3 was acquired with the following primers: Forward: 5'-CTGCAGCAATGACTCAAG-
GAT-3', Reverse: 5'-CTGTGTGAAGTCGTGTTCCCT-3'. pcDNA3.1-HA and CDNA of NLRC3 were digested with BamHI (R0136S, NEB) and EcoRI (R0101S, NEB) at $37^{\circ} \mathrm{C}$ for $4 \mathrm{~h}$, followed by incubation with T4 DNA ligase (M0202S, NEB) at $4^{\circ} \mathrm{C}$ overnight. Then, the vector was transfected into PC12 cells using Lipofectamine 3000 transfection reagent ( $\mathrm{L} 3000075$, Thermo), and stable expression cells were screened using $800 \mu \mathrm{g} / \mathrm{ml} \mathrm{G418}$ (G8160, Solarbio). The NLRC3 knockdown vector was constructed according to a previous study [13]. Pairs of oligos were obtained using the following primers: Forward: 5'-CACCGTCAGACTTCTGTTGACCAAG-3', Reverse: 5'-AACCTTGGTCAACAGAAGTCTGAC-3', and oligos were incubated with T4 PNK (M0201S, NEB) at $37^{\circ} \mathrm{C}$ for $30 \mathrm{~min}$ and $95^{\circ} \mathrm{C}$ for $5 \mathrm{~min}$. Vector and oligos were digested with BsmBI (R0580S, NEB) overnight, and linked with Quick Ligase (M2200S, NEB) to construct the NLRC3 knockdown vector. Then the vector was transfected into 293T cells (CRL-11268) to construct the NLRC3 knockdown vector lentivirus, and stable expression cells were screened using $2 \mathrm{ng} / \mathrm{ml}$ puromycin (P8230, Solarbio).

\section{MTT assay}

Cells were seeded into a 96-well plate at a concentration of $1 \times 10^{5}$, then cells were grouped and treated as described above. The, cells were incubated with Cell Counting Kit-8 (CCK-8) reagent for $3 \mathrm{~h}$. After incubation, the absorbance value at $450 \mathrm{~nm}$ was measured using a CMax Plus microplate reader. The viability rate was calculated with the following formula:

Viability rate $=\left(O D_{\text {experiment }}-O D_{\text {blank }}\right) /\left(O D_{\text {control }}\right.$ $\left.-O D_{\text {blank }}\right)$.

\section{Flow cytometry}

Apoptotic cells were detected using an annexin V/ PI apoptosis detection kit (CA1020, Solarbio). Briefly, cells were grouped and treated as described above, and then cells were diluted at $10^{6} / \mathrm{ml}$ using binding buffer. Cells were incubated with annexin $V$ for 10 min followed by incubation with PI for 5 min. Apoptotic cells were detected using NovoCyte.

\section{RNA extraction}

RNA extraction was performed as recommended by the manufacture's protocol (R1200, Solarbio). Cells were firstly grouped and treated as described above and lysed with lysis buffer, followed by incubation at room temperature for $5 \mathrm{~min}$ and incubation with 
chloroform for $5 \mathrm{~min}$. The water phase was collected after centrifugation at 12,000 rpm for $10 \mathrm{~min}$. After washing with washing buffer, RNA samples were eluted with elution buffer. The concentration of the RNA sample was detected using a Nanodrop. RNA samples were stored at $-80^{\circ} \mathrm{C}$ until the following experiment was performed.

\section{Reverse transcription and quantitative polymerase chain reaction}

Reverse transcription and quantitative polymerase chain reaction ( $\mathrm{PPCR}$ ) were performed as recommended by the manufacture's protocol (T2240, Solarbio). The reaction mixture was made up as recommended, and the reaction was performed with the following steps: reverse transcription: $50^{\circ} \mathrm{C}$ for $15 \mathrm{~min}$, denaturation: $95^{\circ} \mathrm{C}$ for $5 \mathrm{~min}$, with the following steps repeated for 45 cycles: denaturation: $95^{\circ} \mathrm{C}$ for $20 \mathrm{~s}$, annealing: $57^{\circ} \mathrm{C}$ for $25 \mathrm{~s}$. The $\mathrm{qPCR}$ experiment was performed with the following primers: IL-1 $\beta$ : Forward: 5'-AGAAGTACCTGAGCTCGCCA-3', Reverse: 5'-CTGGAAGGAGCACTTCATCTGT-3'; IL-6: Forward: 5'-ACTCACCTCTTCAGAACGAATTG-3', Reverse: 5'-CCATCTTTGGAAGGTTCAGGTTG-3'; TNF- $\alpha$ : Forward: 5'-GCTGCACTTTGGAGTGATCG-3', Reverse: 5'-GAGGGTTTGCTACAACATGGG-3'; IFN- $\gamma$ : Forward: 5'-AGCTGATTCAAATTCCGGTGG-3', Reverse: 5'-TCTCCGGCCTCGAAAGAGAT-3'. Glyceraldehyde 3-phosphate dehydrogenase (GAPDH) was used as an internal control, and data were analysed using the $2^{-\Delta \Delta C t}$ method.

\section{Protein extraction and western blotting}

Cells were firstly grouped and treated as described above. Then, cells were lysed with lysis buffer (RIPA supplied with protein inhibitor cocktail), and protein samples were collected after centrifugation at 12,000 rpm for $10 \mathrm{~min}$. $60 \mu \mathrm{g}$ of protein sample was separated with 10\% SDS-PAGE electrophoresis and then transferred onto a PVDF membrane. Membranes were firstly blocked with $5 \%$ skim milk, and then incubated with primary antibodies at $4^{\circ} \mathrm{C}$ overnight and incubated with secondary antibody at room temperature for $4 \mathrm{~h}$. The expression of each target protein was detected using a chemiluminescent immunoassay.

\section{Enzyme-linked immunosorbent assay}

Cells were firstly grouped and treated as described above, and then cultured medium was collected to perform the enzyme-linked immunosorbent assay
(ELISA) assay. Briefly, samples and standards were added into a 96-well plate and incubated at room temperature for $1 \mathrm{~h}$. After washing with washing buffer, samples were incubated with TMB solution for $10 \mathrm{~min}$ away from light. The absorbance value at $450 \mathrm{~nm}$ was measured using a CMax Plus microplate reader.

\section{Statistical analysis}

Data from each experiment were presented as mean \pm SD. Each experiment was repeated for three times independently. The difference between groups was analysed using one-way ANOVA analysis, and $p<0.05$ was set as a statistical difference.

\section{Results \\ Effect of sevoflurane on proliferation and apoptosis of cells}

The viability rate in the $M, S, 0$, and I groups was $100.0 \pm 6.3,116.2 \pm 7.6,141.1 \pm 9.8$, and $104.5 \pm 6.7$, respectively (Fig. 1A). The viability rate was significantly increased in the $S$ and $O$ group compared with the $M$ group ( $p<0.05)$, and it was significantly increased in the $\mathrm{O}$ group compared with the $\mathrm{S}$ group $(p<0.05)$. The percentage of apoptotic cells in these groups was $31.3 \pm 4.2,24.1 \pm 3.5,14.5 \pm 1.9$, and $28.6 \pm 3.7$, respectively (Fig. 1B). The percentage of apoptotic cells was significantly decreased in the $\mathrm{O}$ group compared with the $M$ and $S$ groups $(p<0.05)$.

\section{Expression of pro-inflammatory factors}

The expression of interleukin $1 \beta$ (IL-1 $\beta$ ) in the M, S, O, and I groups was $1.21 \pm 0.13,1.05 \pm 0.11,0.72$ \pm 0.07 , and $1.37 \pm 0.15$, respectively. The expression of IL-1 $\beta$ was significantly decreased in the 0 group compared with the $M$ and S groups $(p<0.05)$ and was significantly increased in the I group compared with the $S$ group $(p<0.05)$. The expression of interleukin 6 (IL-6) in these groups was $1.34 \pm 0.17,1.19$ $\pm 0.14,0.85 \pm 0.09$, and $1.38 \pm 0.16$, respectively. The expression of IL-6 was significantly decreased in the $\mathrm{O}$ group compared with the $M$ and $S$ groups $(p<0.05)$. The expression of tumour necrosis factor $\alpha$ (TNF- $\alpha)$ in these groups was $1.62 \pm 0.18,1.35$ $\pm 0.15,0.94 \pm 0.09$, and $1.58 \pm 0.17$, respectively. The expression of TNF- $\alpha$ was significantly decreased in the $\mathrm{O}$ group compared with the $\mathrm{M}$ and $\mathrm{S}$ groups $(p<0.05)$. The expression of interferon $\gamma($ IFN- $\gamma)$ in these groups was $1.29 \pm 0.13,1.10 \pm 0.10,0.64 \pm 0.06$, 
and $1.42 \pm 0.15$, respectively. The expression of IFN- $\gamma$ was significantly decreased in the $O$ group compared with the $\mathrm{N}$ group $(p<0.05)$, and it was significantly decreased in the $\mathrm{O}$ group and significantly increased in the I group compared with the S group $(p<0.05)$ (Fig. 2).

\section{Activation of the TRAF6/TLR4/NF- $\kappa$ B signalling pathway}

The expression of TRAF6 in the $M, S, O$, and I groups was $0.64 \pm 0.05,0.41 \pm 0.03,0.17 \pm 0.01$, and $0.56 \pm 0.05$, respectively. Expression of TRAF6 was
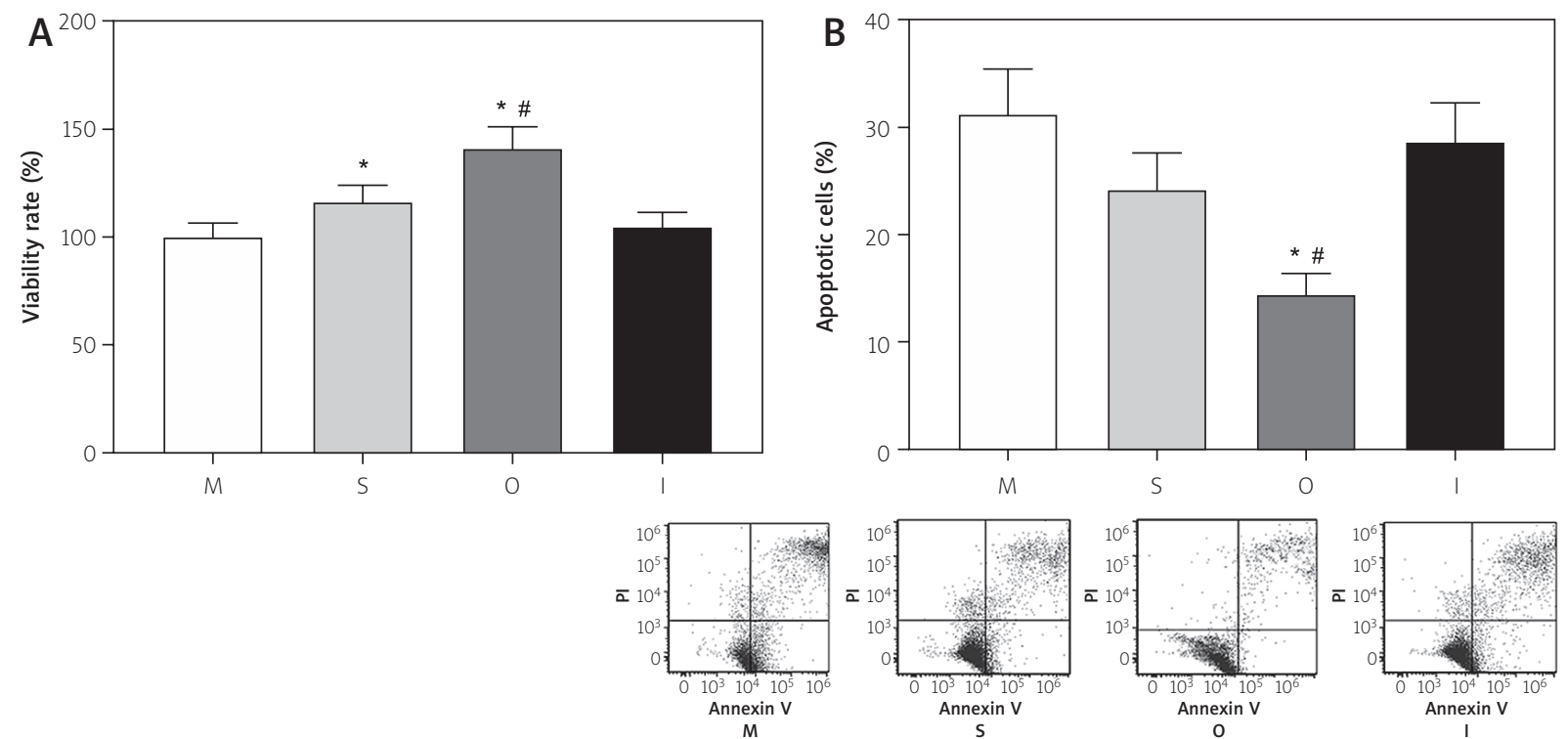

Fig. 1. Effect of sevoflurane on proliferation of cells. A) Detection of cellular viability rate using MTT assay. B) Detection of apoptotic cells using flow cytometry. ${ }^{*} p<0.05$ vs. M group; ${ }^{*} p<0.05$ vs. S group. Data presented as mean $\pm \mathrm{SD}$. Each experiment was repeated three times independently.

A

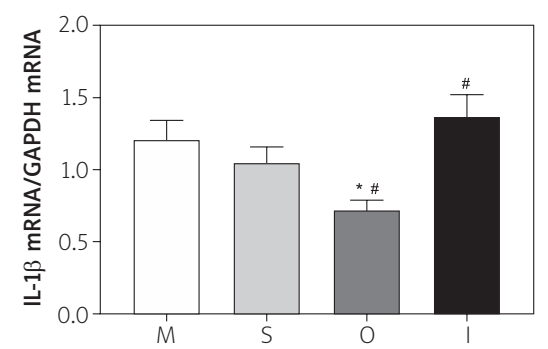

C

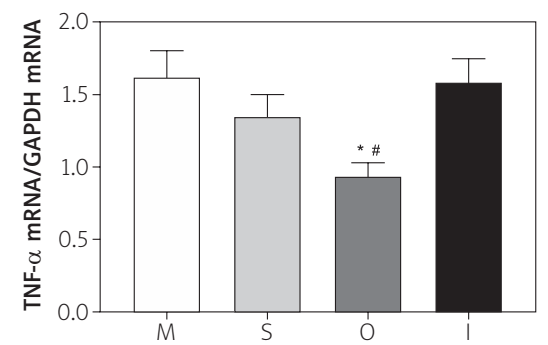

B

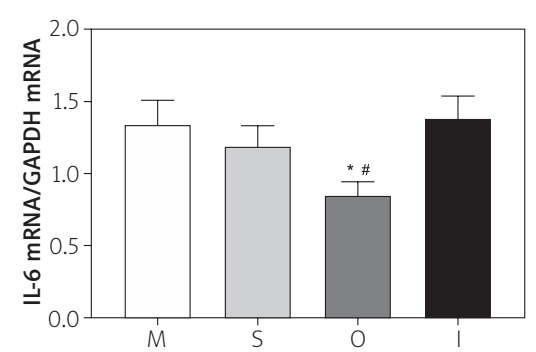

D

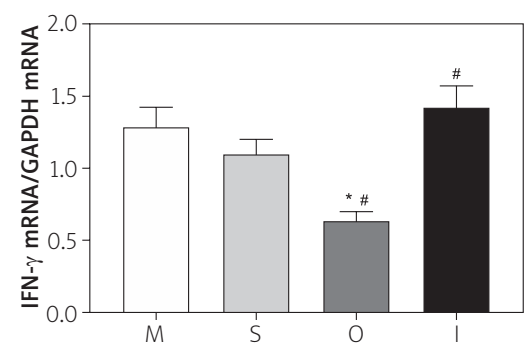

Fig. 2. Detection of A) interleukin $1 \beta$ (IL-1 $\beta$ ), B) interleukin 6 (IL-6), C) tumour necrosis factor $\alpha$ (TNF- $\alpha)$ and D) interferon $\gamma$ (IFN- $\gamma$ ) mRNA expression. ${ }^{*} p<0.05$ vs. M group; ${ }^{*} p<0.05$ vs. S group. Data presented as mean \pm SD. Each experiment was repeated three times independently. 
significantly decreased in the $\mathrm{S}$ and $\mathrm{O}$ group compared with the M group $(p<0.05)$, and the expression was significantly decreased in the $O$ group and significantly increased in the I group compared with the $S$ group $(p<0.05)$. The expression of TLR4 in these groups was $0.84 \pm 0.07,0.74 \pm 0.06,0.34 \pm 0.03$, and $0.65 \pm 0.05$, respectively. Expression of TLR 4 was significantly decreased in the $\mathrm{O}$ and I groups compared with the M group $(p<0.05)$, and it was significantly decreased in the $O$ group compared with the $\mathrm{S}$ group $(p<0.05)$. The expression of TIRAP in these groups was $1.54 \pm 0.13,1.41 \pm 0.12,0.47 \pm 0.04$, and $0.79 \pm 0.07$, respectively. Expression of TIRAP was significantly decreased in the $\mathrm{O}$ and I groups compared with the $\mathrm{M}$ and $\mathrm{S}$ groups $(p<0.05)$. The expression of MyD88 in these groups was $1.08 \pm 0.09,1.10 \pm 0.09$, $0.57 \pm 0.05$, and $0.99 \pm 0.08$, respectively. Expression of MyD88 was significantly decreased in the 0 group compared with the $M$ and $S$ groups $(p<0.05)$. The ratio of $\mathrm{p}-\mathrm{NF}-\mathrm{kB} / \mathrm{NF}-\mathrm{\kappa B}$ in these groups was 0.50 $\pm 0.04,1.10 \pm 0.09,1.57 \pm 0.13$, and $0.91 \pm 0.07$, respectively. The ratio of $\mathrm{p}-\mathrm{NF}-\mathrm{kB} / \mathrm{NF}-\mathrm{kB}$ was significantly increased in all treatment groups compared with the $M$ group $(p<0.05)$, and it was significantly increased in the $\mathrm{O}$ group and significantly decreased in the I group compared with the $\mathrm{S}$ group $(p<0.05)$ (Fig. 3).

\section{Expression of target molecules of the TRAF6/TLR4/NF- $\kappa$ B signalling pathway}

The expression of PARP- 1 in the $\mathrm{M}, \mathrm{S}, \mathrm{O}$, and I groups was $1.17 \pm 0.10,1.05 \pm 0.08,0.75 \pm 0.06$, and $1.54 \pm 0.13$, respectively. Expression of PARP-1 was significantly decreased in the $\mathrm{O}$ group and significantly increased in the I group $(p<0.05)$ compared with the $M$ and $S$ groups. The expression of SIRT1 in these
A

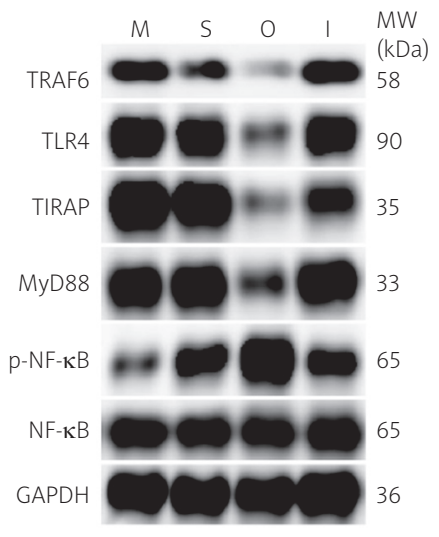

B
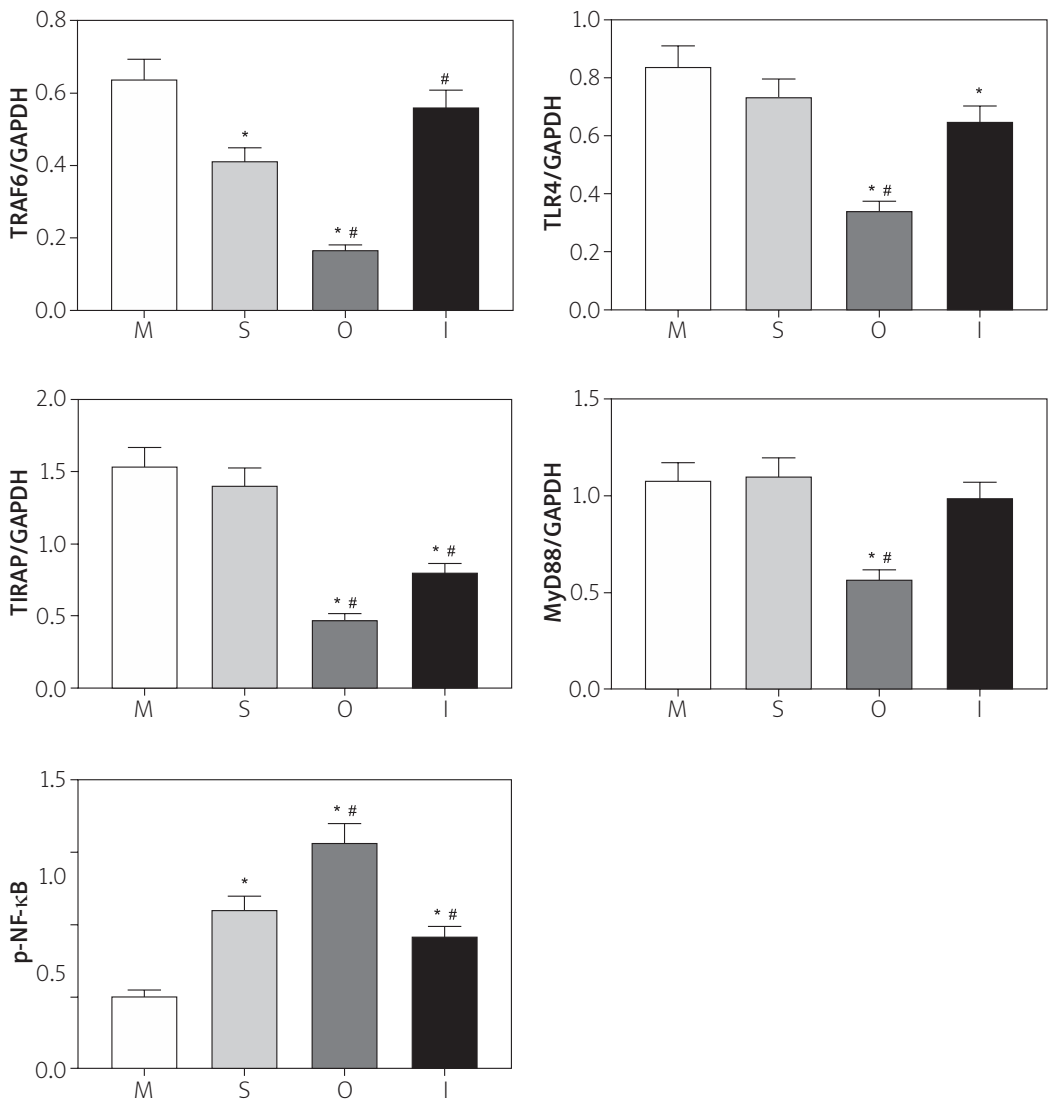

Fig. 3. Expression of TRAF6/TLR4 signalling pathway. A) Western blotting analysis of TRAF6, TLR4, TIRAP,

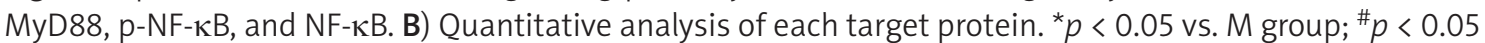
vs. $S$ group. Data presented as mean $\pm S D$. Each experiment was repeated three times independently. 
groups was $0.38 \pm 0.03,0.76 \pm 0.06,1.04 \pm 0.09$, and $0.60 \pm 0.05$, respectively. Expression of SIRT1 was significantly increased in all treatment groups $(p<0.05)$ and was significantly increased in the $O$ group and significantly decreased in the I group $(p<0.05)$ compared with the $S$ group. The expression of ROCK 2 in these groups was $0.93 \pm 0.08,0.84 \pm 0.07,0.37 \pm 0.03$, and $0.92 \pm 0.08$, respectively. Expression of ROCK2 was significantly decreased in the 0 group $(p<0.05)$ compared with the $\mathrm{M}$ and $\mathrm{S}$ groups. The expression of eNOS in these groups was $0.68 \pm 0.06,0.90 \pm 0.08$, $1.29 \pm 0.10$, and $0.84 \pm 0.07$, respectively. Expression of eNOS was significantly increased in all treatment groups $(p<0.05)$ and was significantly increased in the $\mathrm{O}$ group $(p<0.05)$ compared with the $\mathrm{S}$ group (Fig. 4)

\section{Secretion of pro-inflammatory factors in culture medium}

The concentration of IL-1 $\beta$ in the $M, S, O$, and I groups was $82.3 \pm 9.7,67.5 \pm 6.8,42.8 \pm 5.2$, and 86.4 $\pm 10.3 \mathrm{pg} / \mathrm{ml}$, respectively. The concentration of IL-1 $\beta$ was significantly decreased in the $O$ group compared with the $M$ and $S$ groups $(p<0.05)$. The concentration of IL- 6 in these groups was $224.3 \pm 17.3,184.6 \pm 15.4$, $135.7 \pm 12.6$, and $213.7 \pm 16.8 \mathrm{pg} / \mathrm{ml}$, respectively. The concentration of IL-6 was significantly decreased in the $\mathrm{S}$ and $\mathrm{O}$ groups compared with the $\mathrm{M}$ group $(p<0.05)$, and it was significantly decreased in the $\mathrm{O}$ group compared with the $\mathrm{S}$ group $(p<0.05)$. The concentration of TNF- $\alpha$ in these groups was 382.1 $\pm 27.6,321.5 \pm 21.4,248.6 \pm 16.9$, and $379.8 \pm 26.5 \mathrm{pg} / \mathrm{ml}$, respectively. The concentration of TNF- $\alpha$ was significantly decreased in the $\mathrm{S}$ and $\mathrm{O}$ groups compared with the M group ( $p<0.05$ ), and it was significantly decreased in the $O$ group and significantly increased in the I group compared with the $S$ group $(p<0.05)$. The concentration of IFN- $\gamma$ in these groups was 21.3 $\pm 3.8,17.0 \pm 2.9,11.6 \pm 2.1$, and $22.5 \pm 3.6 \mathrm{ng} / \mathrm{ml}$, respectively. The concentration of IFN- $\gamma$ was significantly decreased in the $O$ group compared with the $M$ and $\mathrm{S}$ groups $(p<0.05)$ (Fig. 5).

\section{Discussion}

Acute ischaemic stroke, accounts for more than $80 \%$ of stroke cases and is one of the major causes of mortality and disability around the world [9]. Sevoflurane was firstly discovered to exert a protective role in ischaemic myocardium in 2013 [47], and a recent study found that sevoflurane treatment enhanced the tolerance of cells to cerebral ischaemic damage, as well as a reduction in neurologic deficit scores, infarction volume, and oxidative stress levels [23]. However, the detailed mechanism was
A

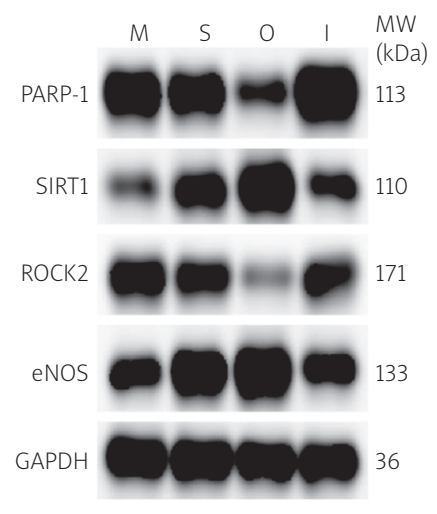

B
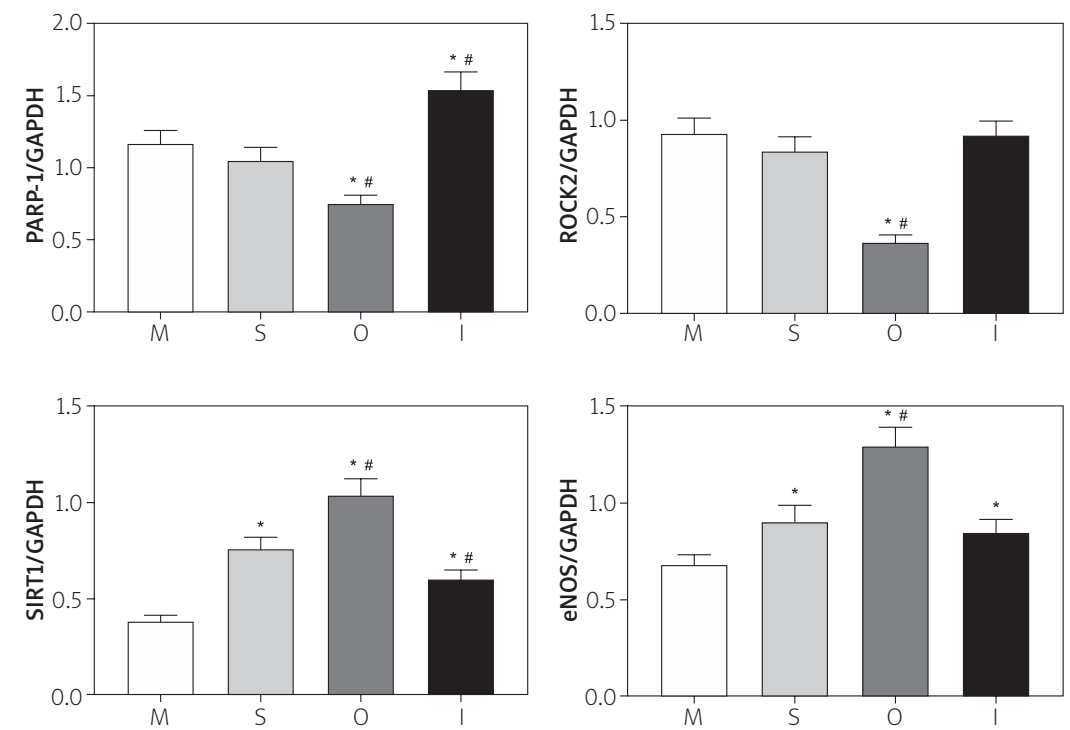

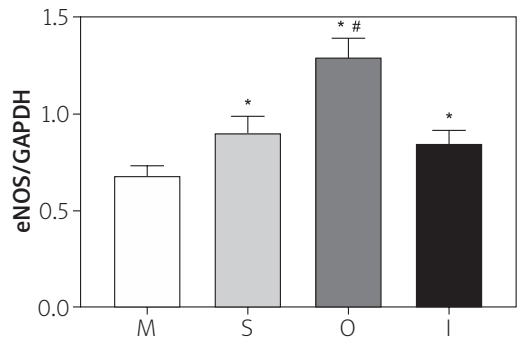

Fig. 4. Expression of PARP-1, SIRT1, ROCK2 and eNOS in each group. ${ }^{*} p<0.05$ vs. M group; ${ }^{*} p<0.05$ vs. $S$ group. Data presented as mean \pm SD. Each experiment was repeated three times independently. 
A
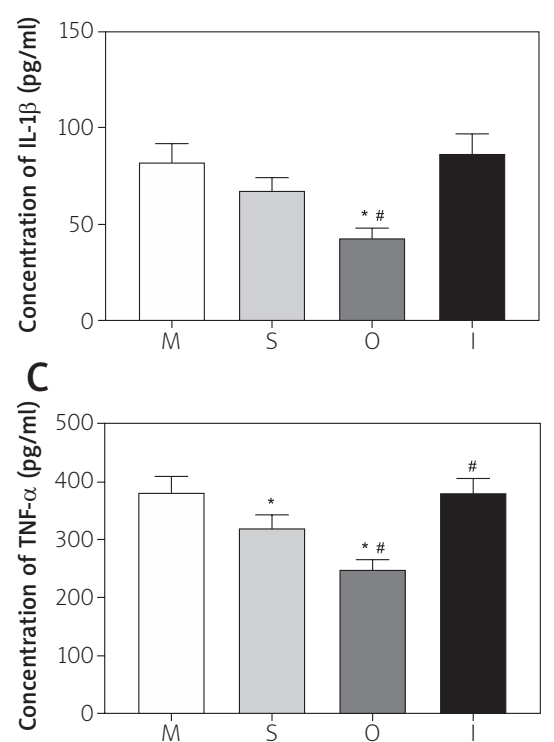

B

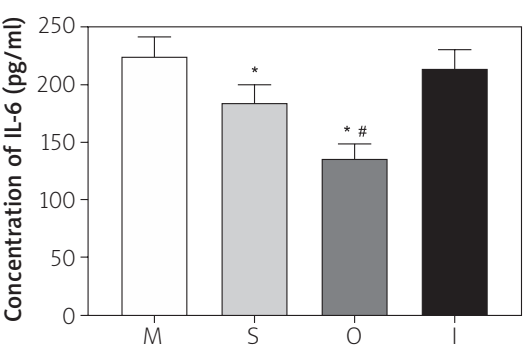

D

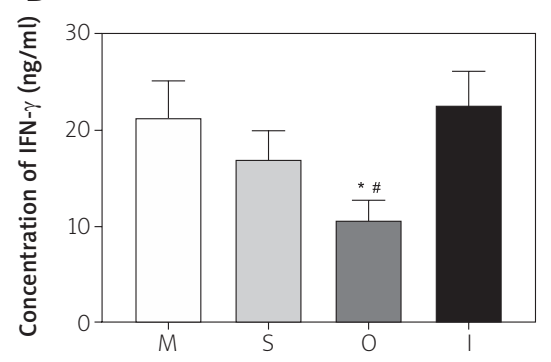

Fig. 5. Detection of A) interleukin $1 \beta$ (IL-1 $\beta$ ), B) interleukin 6 (IL-6), C) tumour necrosis factor $\alpha$ (TNF- $\alpha$ ) and D) interferon $\gamma($ IFN- $\gamma)$ concentration. ${ }^{*} p<0.05$ vs. M group; ${ }^{*} p<0.05$ vs. S group. Data was presented as mean \pm SD. Each experiment was repeated three times independently.

not fully understood. NLRC3 is the most commonly described members of the NLR family, and it has been proven to regulate the activation of the NF- $\kappa B$ signalling pathway via the degradation of $I_{\kappa} \mathrm{B} \alpha$ [37]. A recent study found that NLRC3 plays an important role in regulating the innate immune response of the host [27]. Thus, we speculated that NLRC3 might contribute to the therapeutic effect of sevoflurane.

The recovery of blood flow after cerebral ischaemic injury leads to the activation of inflammatory cascades, such as the infiltration of inflammatory cells and release of inflammatory mediators, further leading to the death of neuron cells [38]. Here, we detected the expression of IL- $1 \beta, \mathrm{IL}-6, \mathrm{IFN}-\gamma$, and TNF- $\alpha$ in each group of cells.

Interleukin $1 \beta$ is constitutively expressed in central nervous system (CNS) and regulates the activity of neurotrophic factor and ion channels [42]. A previous study found that the expression of IL-1 $\beta$ was elevated after ischaemic stroke and reached the peak at 12-24 h [7]. Using gene knockout mice, researchers found that IL-1 $\beta$ aggravates the pathology of ischaemia, while knockout of IL-1 $\beta$ would reduce the infarct volumes [5], and a further study noticed that administration of IL-1 $\beta$ before MCAO would worsen the outcome in rodents [31]. Interleukin 6 is also expressed in normal CNS and regulates homeosta- sis via the classical signalling pathway. Significant elevation of IL- 6 was also observed after ischaemic damage, and differing from IL-1 $\beta$, IL- 6 elevation occurred from 6 to $12 \mathrm{~h}$ after injury [11]. Another study found that the concentration of IL- 6 in serum was increased in the first $24 \mathrm{~h}$ with increasing infarct size, and this process not only occurred in the acute phase but also at later time points [33]. The concentration of TNF- $\alpha$ remains at a low level in CNS under normal conditions and regulates transmission and synaptic plasticity [39]. TNF- $\alpha$ is secreted by microglia in the early phase after ischaemia and by macrophages in the late phase [19], and after ischaemia the concentration of TNF- $\alpha$ is significantly elevated at 12-24 $\mathrm{h}$ and remains at a high level for days [20]. Interferon $\gamma$ is another regulator of the inflammatory response process in the CNS; however, the role of IFN- $\gamma$ in cerebral disease such as ischaemia and trauma is not clear. A previous study found that there is no relevant correlation with IFN- $\gamma$ and focal ischaemia in mice [21], arguing against IFN- $\gamma$ as the key regulator of injury after focal ischaemia. T cells were considered the main effector of the antigenindependent innate inflammatory response after the acute phase of ischaemic inflammation, which is mainly regulated by IFN- $\gamma$. Interferon $\gamma$ is regarded as a neurotoxic factor because IFN- $\gamma$ directly induces 
neuronal cell death [25]. Additionally, another study found that regulatory $T$ cells might present a neuroprotective effect via suppression of the neurotoxic function of IFN- $\gamma$ through expression of IL-10 [25]. Here, we found that the expression of these factors was decreased after application of NLRC3 overexpression, indicating a protective role in an ischaemia model.

Many studies have shown that ischaemia-reperfusion injury induced multiple pathological alterations, including metabolism abnormality, inflammatory reaction, and oxidative stress leading to the regeneration of neuron cells [48]. A previous study proved that the TLR signalling pathway plays an important role in the development of ischaemiareperfusion injury, which is activated by DNA damage and protein degradation [2]. NF- $\kappa B$ could be activated by TRAF6 to regulate the inflammatory response process via the MyD88-dependent or -independent pathway. In an MCAO model, researchers noticed that brain oedema and TRAF6 expression were obviously observed, and after the application of TRAF6 inhibitor, the infarction size and the degree of oedema were reduced, as well as the expression of TRAF6 [26]. Further study found that the effect of TRAF6 in ischaemia-reperfusion injury was mainly mediated by the TLR4 signalling pathway [49]. Additionally, TRAF6 is the only member of the TRAF family that can regulate the TNF- $\alpha$ and IL- $1 \beta$ signalling pathway [16], and thus the expression of TRAF6 is closely related to the regulation of the cellular apoptosis process after ischaemia-reperfusion injury [32], and the reduction of TRAF6 expression leads to the inactivation of $\mathrm{NF}-\kappa \mathrm{B}$ signalling pathway as well as the reduction of cytokine production [10]. In order to activate downstream pathways, TLRs need to bind with a variety of adaptor proteins, including TIR-containing adaptor protein (TIRAP) and MyD88. Under oxidative stress, TRIAP binds with PIP2, leading to the activation of MyD88 and its downstream molecular, NF- $\kappa B$ [36]. A recent study proved that TIRAP could facilitate the interaction of TLR4 and MyD88, indicating that TRIAP is critical for the formation of endosomal compartments [6]. Another researcher found that atorvastatin inhibits the inflammatory response process due to its ability to inactivate caspase- 1 and further inhibit the secretion of IL-1 $\beta$, and these effects might be mediated by the TLR4/MyD88/NF-KB pathway [17], indicating that MyD88 is an important adaptor of the TLR4 signalling pathway [3].
$\mathrm{NF}-\kappa \mathrm{B}$ is the central regulator of the inflammatory response, which is regulated by multiple signalling pathways. Besides TLR4/TRAF6, poly(adenosine diphosphateribose) polymerase-1 (PARP-1)/sirtuin 1 (SIRT1) is another possible pathway involved in the regulation of NF- $\kappa B$ activity [40]. It is well-known that activity of PARP leads to the reduction of the intracellular concentration of $\mathrm{NAD}^{+}[1]$, which is correlated with the reduction of SIRT1 activity because SIRT1 is a NAD ${ }^{+}$-dependent protein deacetylase [12]. Further study found that inflammation-related diseases commonly occurred due to the overexpression of PARP-1 [29], and oxidative stress status induced by the inflammatory response leads to the activation of PARP, resulting in the strain of $\mathrm{NAD}^{+}$and further inhibition of SIRT1 activity. Reduction of SIRT1 activity further induces the dysfunction of mitochondria, a possible leading cause of chronic inflammatory and metabolic diseases [30]. Rho-associated protein kinase (ROCK) is a downstream target of Rho GTPases, a kind of serine-threonine protein kinase, and is divided into two subtypes: ROCK1 and ROCK2 [18]. ROCK is ubiquitously expressed and performs an important role in neurological diseases including cerebral injury [15]. A previous study found that ROCK2 is activated after ischaemia in a rat model of cerebral ischaemia, and another study found that myosin-binding subunit, a substrate of ROCK2, is elevated in cerebral ischaemia rats and reaches a peak at six weeks, presenting a similar trend to changes in ROCK2 expression [44]. Activation of ROCK2 leads to the degradation of many downstream effectors of the PI3K/AKT signalling pathway,

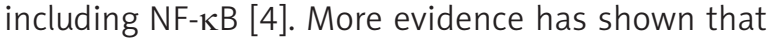
endothelial nitric oxide synthase (eNOS), an important regulator of endothelial function, is regulated by the RhoA/ROCK pathway [43]. Inhibition of RhoA geranylgeranylation would decrease the activation of RhoA, leading to the reduction of ROCK activity and the upregulation of eNOS [22]. Additionally, direct inhibition of ROCK using ROCK inhibitor also increases the expression of eNOS [35]; because eNOS is a protector of the vasculature, these findings show that ROCK might be a protector of cerebral ischaemia. Based on these findings, we speculated that overexpression of NRLC3 might enhance the therapeutic effect of sevoflurane on ischaemia reperfusion through inhibition of the inflammatory response process via inhibition of the TRAF6/TLR4 signalling pathway. 


\section{Disclosure}

The authors declare no conflict of interest.

\section{References}

1. Bai P, Cantó C. The Role of PARP-1 and PARP-2 enzymes in metabolic regulation and disease. Cell Metab 2012; 16: 290-295.

2. Barr TL, Conley Y, Ding J, Dillman A, Warach S, Singleton A, Matarin M. Genomic biomarkers and cellular pathways of ischemic stroke by RNA gene expression profiling. Neurology 2010; 75: 1009-1014.

3. Barton GM, Medzhitov R. Toll-like receptor signaling pathways. Science 2003; 300: 1524-1525.

4. Begum N, Sandu OA, Ito M, Lohmann SM, Smolenski A. Active Rho Kinase (ROK-alpha) associates with insulin receptor substrate-1 and inhibits insulin signaling in vascular smooth muscle cells. J Biol Chem 2002; 277: 6214-6222.

5. Boutin H, LeFeuvre RA, Horai R, Asano M, Iwakura Y, Rothwell NJ. Role of IL-1alpha and IL-1beta in ischemic brain damage. J Neurosci 2001; 21: 5528-5534.

6. Brubaker SW, Bonham KS, Zanoni I, Kagan JC. Innate immune pattern recognition: a cell biological perspective. Annu Rev Immunol 2015; 33: 257-290.

7. Clausen BH, Lambertsen KL, Babcock AA, Holm TH, DagnaesHansen F, Finsen B. Interleukin-1beta and tumor necrosis factor-alpha are expressed by different subsets of microglia and macrophages after ischemic stroke in mice. J Neuroinflammation 2008; 5: 46.

8. Eberspächer E, Eckel B, Engelhard K, Müller K, Hoffman WE, Blobner M, Werner C. Effects of sevoflurane on cognitive deficit, motor function, and histopathology after cerebral ischemia in rats. Acta Anaesthesiol Scand 2009; 53: 774-782.

9. Go AS, Mozaffarian D, Roger VL, Benjamin EJ, Berry JD, Borden WB, Bravata DM, Dai S, Ford ES, Fox CS, Franco S, Fullerton HJ, Gillespie C, Hailpern SM, Heit JA, Howard VJ, Huffman MD, Kissela BM, Kittner SJ, Lackland DT, Lichtman JH, Lisabeth LD, Magid D, Marcus GM, Marelli A, Matchar DB, McGuire DK, Mohler ER, Moy CS, Mussolino ME, Nichol G, Paynter NP, Schreiner PJ, Sorlie PD, Stein J, Turan TN, Virani SS, Wong ND, Woo D, Turner MB; American Heart Association Statistics Committee and Stroke Statistics Subcommittee. Heart Disease and Stroke statistics - 2013 Update: a report from the American Heart Association. Circulation 2013; 127: e6-e245.

10. Gohda J, Matsumura T, Inoue J. Cutting Edge: TNFR-associated factor (TRAF) 6 is essential for MyD88-dependent pathway but not toll/IL-1 receptor domain-containing adaptor-inducing IFNbeta (TRIF)-dependent pathway in TLR signaling. I Immunol 2004; 173: 2913-2917.

11. Grønhøj MH, Clausen BH, Fenger CD, Lambertsen KL, Finsen B. Beneficial potential of intravenously administered IL-6 in improving outcome after murine experimental stroke. Brain Behav Immun 2017; 65: 296-311.

12. Houtkooper RH, Auwerx J. Exploring the therapeutic space around NAD+. J Cell Biol 2012; 199: 205-209.

13. Hwang SH, Yeom H, Lee M. ATG5 Knockout promotes paclitaxel sensitivity in drug-resistant cells via induction of necrotic cell death. Korean J Physiol Pharmacol 2020; 24: 233-240.
14. Jiang Q, Gu S. Sevoflurane postconditioning reduces hypoxiareoxygenation injury in $\mathrm{H} 9 \mathrm{C} 2$ embryonic rat cardiomyocytes and targets the STRADA gene by upregulating microRNA-107. Med Sci Monit 2020; 26: e920849.

15. Koch JC, Tatenhorst L, Roser AE, Saal KA, Tönges L, Lingor P. ROCK inhibition in models of neurodegeneration and its potential for clinical translation. Pharmacol Ther 2018; 189: 1-21.

16. Kobayashi T, Walsh MC, Choi Y. The role of TRAF6 in signal transduction and the immune response. Microbes Infect 2004; 6: 1333-1338.

17. Kong F, Ye B, Lin L, Cai X, Huang W, Huang Z. Atorvastatin suppresses NLRP3 inflammasome activation via TLR4/MyD88/ NF- $\mathrm{KB}$ signaling in PMA-stimulated THP-1 monocytes. Biomed Pharmacother 2016; 82: 167-172.

18. Lai AY, McLaurin J. Rho-associated protein kinases as therapeutic targets for both vascular and parenchymal pathologies in Alzheimer's disease. J Neurochem 2018; 144: 659-668.

19. Lambertsen KL, Clausen BH, Babcock AA, Gregersen R, Fenger C, Nielsen HH, Haugaard LS, Wirenfeldt M, Nielsen M, DagnaesHansen F, Bluethmann H, Faergeman NJ, Meldgaard M, Deierborg T, Finsen B. Microglia protect neurons against ischemia by synthesis of tumor necrosis factor. J Neurosci 2009; 29: 13191330.

20. Lambertsen KL, Biber K, Finsen B. Inflammatory cytokines in experimental and human stroke. J Cereb Blood Flow Metab 2012; 32: 1677-1698.

21. Lambertsen KL, Gregersen R, Meldgaard M, Clausen BH, Heibøl EK, Ladeby R, Knudsen J, Frandsen A, Owens T, Finsen B. A role for interferon-gamma in focal cerebral ischemia in mice. J Neuropathol Exp Neurol 2004; 63: 942-955.

22. Laufs U, Liao JK. Post-transcriptional regulation of endothelial nitric oxide synthase mRNA stability by rho GTPase. J Biol Chem 1998; 273: 24266-24271.

23. Li B, Sun J, Lv G, Yu Y, Wang G, Xie K, Jiao Y, Yu Y. Sevoflurane postconditioning attenuates cerebral ischemia-reperfusion injury via protein kinase B/nuclear factor-erythroid 2-related factor 2 pathway activation. Int I Dev Neurosci 2014; 38: 79-86.

24. Li ZT, Liu H, Zhang WQ. NLRC3 alleviates hypoxia/reoxygenation induced inflammation in RAW264.7 cells by inhibiting K63linked ubiquitination of TRAF6. Hepatobiliary Pancreat Dis Int 2020; S1499-3872: 30078-30083.

25. Liesz A, Payer ES, Veltkamp C, Doer H, Sommer C, Rivest S, Giese T, Veltkamp R. Regulatory T cells are key cerebroprotective immunomodulators in acute experimental stroke. Nat Med 2009; 15: 192-199.

26. Liu ZJ, He D, Zhang XJ, Li Y, Zhu C, Dong L, Zhang X, Xing X, Wang C, Qiao H, Chen L. Neuroprotective effect of early and short-time applying sophoridine in PMCAO rat brain: down-regulated TRAF6 and up-regulated p-ERK1/2 expression, ameliorated brain infarction and edema. Brain Res Bull 2012; 88: 379-384.

27. Lu Z, Jinyao M, Karen SV, Petrucelli A, Gregory SM, Zhang Z, Schneider M, Jiang Y, Fitzgerald KA, Ouyang S, Liu ZJ, Damania B, Shu HB, Duncan JA, Ting JP. NLRC3, a member of the NLR family of proteins, is a negative regulator of innate immune signaling induced by the DNA sensor STING. Immunity 2014; 40: 329-341.

28. Lucas SM, Rothwell NJ, Gibson RM. The role of inflammation in CNS injury and disease. Br J Pharmacol 2006; 147: S232-240. 
29. Mangerich A, Herbach N, Hanf B, Fischbach A, Popp O, MorenoVillanueva M, Bruns OT, Bürkle A. Inflammatory and age-related pathologies in mice with ectopic expression of human PARP-1. Mech Ageing Dev 2010; 131: 389-404.

30. Massudi H, Grant R, Braidy N, Guest J, Farnsworth B, Guillemin GJ. Age-associated changes in oxidative stress and NAD+ metabolism in human tissue. PLoS One 2012; 7: e42357.

31. McColl BW, Rothwell NJ, Allan SM. Systemic inflammatory stimulus potentiates the acute phase and CXC chemokine responses to experimental stroke and exacerbates brain damage via interleukin-1- and neutrophil-dependent mechanisms. J Neurosci 2007; 27: 4403-4412.

32. Nakka VP, Gusain A, Mehta SL, Raghubir R. Molecular mechanisms of apoptosis in cerebral ischemia: multiple neuroprotective opportunities. Mol Neurobiol 2008; 37: 7-38.

33. Nguyen TV, Frye JB, Zbesko JC, Stepanovic K, Hayes M, Urzua A, Serrano G, Beach TG, Doyle KP. Multiplex immunoassay characterization and species comparison of inflammation in acute and non-acute ischemic infarcts in human and mouse brain tissue. Acta Neuropathol Commun 2016; 4: 100.

34. Pape M, Engelhard K, Eberspächer E, Hollweck R, Kellermann K, Zintner S, Hutzler P, Werner C. The long-term effect of sevoflurane on neuronal cell damage and expression of apoptotic factors after cerebral ischemia and reperfusion in rats. Anesth Analg 2006; 103: 173-179.

35. Rikitake Y, Kim HH, Huang ZH, Seto M, Yano K, Asano T, Moskowitz MA, Liao JK. Inhibition of rho kinase (ROCK) leads to increased cerebral blood flow and stroke protection. Stroke 2005; 36: 2251-2257.

36. Schmitz G, Orsó E. CD14 signalling in lipid rafts: new ligands and co-receptors. Curr Opin Lipidol 2002; 13: 513-521.

37. Schneider M, Zimmermann AG, Roberts RA, Zhang L, Swanson KV, Wen H, Davis BK, Allen IC, Holl EK, Ye Z, Rahman AH, Conti BJ, Eitas TK, Koller BH, Ting JP. The innate immune sensor NLRC3 attenuates Toll-like receptor signaling via modification of the signaling adaptor TRAF6 and transcription factor NF- $\kappa \mathrm{B}$. Nat Immunol 2012; 13: 823-831.

38. Seiichiro S, Takashi S. Inflammation and neural repair after ischemic brain injury. Neurochem Int 2019; 130: 104316.

39. Stellwagen D, Malenka RC. Synaptic scaling mediated by glial TNF-alpha. Nature 2006; 440: 1054-1059.

40. Tornatore L, Thotakura AK, Bennett J, Moretti M, Franzoso G. The nuclear factor kappa B signaling pathway: integrating metabolism with inflammation. Trends Cell Biol 2012; 22: 557-566.

41. Tymianski M. Novel approaches to neuroprotection trials in acute ischemic stroke. Stroke 2013; 44: 2942-2950.

42. Viviani B, Bartesaghi S, Gardoni F, Vezzani A, Behrens MM, Bartfai T, Binaglia M, Corsini E, Di Luca M, Galli CL, Marinovich M. Interleukin-1beta enhances NMDA receptor-mediated intracellular calcium increase through activation of the Src family of kinases. J Neurosci 2003; 23: 8692-8700.

43. Wolfrum S, Dendorfer A, Rikitake Y, Stalker TJ, Gong Y, Scalia R, Dominiak P, Liao JK. Inhibition of Rho-kinase leads to rapid activation of phosphatidylinositol 3-kinase/protein kinase Akt and cardiovascular protection. Arterioscler Thromb Vasc Biol 2004; 24: 1842-1847.
44. Yan YY, Wang XM, Jiang Y, Chen H, He JT, Mang J, Shao YK, Xu ZX. The role of Rho/Rho-kinase pathway and the neuroprotective effects of fasudil in chronic cerebral ischemia. Neural Regen Res 2015; 10: 1441-1449.

45. Zhang L, Mo J, Swanson K, Petrucelli A, Gregory SM, Zhang Z, Schneider M, Jiang Y, Fitzgerald KA, Ouyang S, Liu ZJ, Damania B, Shu HB, Duncan JA, Ting JP. NLRC3, a member of the NLR family of proteins, is a negative regulator of innate immune signaling induced by the DNA sensor STING. Immunity 2014; 40: 329-341.

46. Zhou YP, Li GC. Kaempferol protects cell damage in in vitro ischemia reperfusion model in rat neuronal PC12 cells. Biomed Res Int 2020; 2020: 2461079.

47. Zhu MH, Yan M. Advances in the study of cell signaling pathways and downstream effectors in volatile anesthetic postconditioning-induced cardioprotection. Int J Anesth Resu 2013; 34: 177-181.

48. Zhu WB, Casper A, Libal NL, Murphy SJ, Bodhankar S, Offner $H$, Alkayed NJ. Preclinical evaluation of recombinant T cell receptor ligand RTL1000 as a therapeutic agent in ischemic stroke. Transl Stroke Res 2015; 6: 60-68.

49. Wu D, Lee YC, Liu HC, Yuan RY, Chiou HY, Hung CH, Hu CJ. Identification of TLR downstream pathways in stroke patients. Clin Biochem 2013; 46: 1058-1064. 